\title{
La primera cátedra cubana de Historia del Derecho: notas para su estudio*
} The first Cuban Lecture of

\section{Fabricio Mulet Martínez ${ }^{* *}$}

\section{RESUMEN}

El presente artículo trata sobre la cátedra de Historia General del Derecho Español creada en la Universidad de La Habana, a finales del siglo XIX, cuando Cuba se encontraba aún bajo el dominio colonial español. La inserción de dicha materia obedeció, en primer término, a su inclusión en los planes de estudios universitarios aprobados en la Península Ibérica, hechos por demás extensivos a la isla. Esto obedeció a una serie de factores como la modernización de la enseñanza universitaria, el desarrollo de corrientes nacionalistas y la influencia de la Escuela Histórica del Derecho. En este artículo se analizarán las condiciones particulares que propiciaron el interés por los estudios históricojuridicos en Cuba, asi como el programa de la materia señalada y la obra de los profesores que ostentaron la titularidad de dicha cátedra.

PALABRAS CLAVE: Historia del derecho, Cuba, siglo XIX, ciencia jurídica.

\begin{abstract}
This article deals with the General History Lecture of Spanish Law created at the University of Havana, at the end of the Nineteen Century, when Cuba was still under Spanish Colonial Rule. The addition of this subject obeyed, in the first place, to its addition in the University studies plans approved in the Iberian Peninsula, taught extensively on the island. This was due to a series of factors such as the modernization of University Education, the development of nationalist trends and the influence of the Historical School of Law. In this article we will analyze the particular conditions that led to the interest in Historical-Juridical Studies in Cuba, as well as the program of the abovemention subject and the work of the professors who held the chair of said lecture.
\end{abstract}

KEY WORDS: History of Law, Cuba, Nineteenth Century, Legal Science.

\footnotetext{
* Artículo de investigación. Recibido el 19 de febrero de 2018 y aceptado para su publicación el 4 de junio de 2018.

** Doctorando en la Universidad de Huelva, España. (fabricio.mulet87@gmail.com) orcid.org/0000-0002-0716-0133
} 


\section{SUMARIO}

1. Introducción

2. La Real y Pontificia Universidad de San Gerónimo de la Habana

3. Los inicios de los estudios histórico-juridicos en Cuba

4. La Cátedra de Historia General del Derecho Español

5. Conclusiones

\section{Introducción}

El siglo XIX es fundamental en la configuración de la cultura jurídica cubana. Está caracterizado por una marcada influencia de los adelantos científicos y de las nuevas corrientes filosóficas que en el resto del mundo se suscitaban, las cuales entraban a la isla de la mano de una oligarquía descollante que tenía los ojos puestos en el ideario burgués europeo. En el sector universitario se hicieron visibles algunas tendencias encaminadas a la modernización de la enseñanza jurídica y se generó un importante debate en torno a ello. Si bien este fenómeno fue un eco de posturas similares perceptibles en la metrópoli española, en Cuba estuvo motivado por causas endémicas. Luego de la secularización de la enseñanza universitaria en 1842, bajo el influjo de tendencias como la marcada por la Escuela Histórica del Derecho, en Cuba aparecieron las primeras expresiones bibliográficas de corte histórico-jurídico, hasta que en 1883 se incluirá en los planes de estudio la asignatura Historia General del Derecho. Curiosamente, este tema no ha sido para nada abordado por la historiografía cubana, ni siquiera durante el período prerrevolucionario, más cercano en tiempo al siglo XIX.

El objetivo del presente trabajo es analizar los elementos determinantes en el surgimiento y desarrollo de la historia del derecho como disciplina jurídica en la Cuba decimonónica. Haremos énfasis en la Cátedra de Historia General del Derecho creada a la luz del Plan Gamazo, y utilizaremos los métodos histórico-jurídico y jurídico-doctrinal. El ochocientos jurídico cubano comprende un rico universo poco explorado en toda su complejidad. La suerte de la historia del derecho en Cuba durante el siglo mencionado, como la de la enseñanza jurídica en general, estuvo estrechamente ligada a los avatares y vaivenes acontecidos en España. Debido a su condición colonial, en Cuba regían prácticamente los mismos planes de estudio que en la metrópoli peninsular, se utilizó prácticamente la misma bibliografía. Incluso, la consolidación de los estudios histórico-jurídicos se suscitó en ambos casos en medio de circunstancias muy similares. 
Dado que las principales influencias cubanas en cuanto a ciencia y educación jurídicas provinieron generalmente de España, en los planes de estudio no se insertó una historia general del derecho hasta 1883, cuando la instauraron los ibéricos. Por consecuencia era una historia del derecho español. Sin embargo, este proceso no se limitó a ser un simple reflejo del ibérico. Tuvo particularidades muy propias. Fue el resultado de un palpable cambio de discurso científico en la isla. Los orígenes y el desenvolvimiento de la disciplina objeto de este trabajo no pueden examinarse de manera aislada sino en relación dialéctica con una serie de condicionamientos de índole social, económica y política, encuadrados en un escenario histórico específico y determinados por tendencias culturales concretas. Por tales motivos, el estudio propuesto no puede circunscribirse al área de la mencionada cátedra. Es cierto que esta será el eje central del análisis, al igual que la labor de los profesores José María Céspedes y Orellano y Juan Francisco 0'Farril y Chappotín, quienes fueron sus titulares durante su periodo de existencia. También será necesario detenerse en sus antecedentes jurídico-historiográficos, donde destaca la obra de Antonio Prudencio López, autor de uno de los primeros manuales del continente.

Además del interés que podrá tener el tema para la historiografía cubana, al ser un aspecto poco investigado, es justo que su repercusión no se restrinja a un plano eminentemente localista sino que su interés podría trascender al contexto latinoamericano. Puede esperarse que el presente trabajo contribuya a vislumbrar algunas claves esenciales del surgimiento y desarrollo de la historia del derecho en América Latina, debido a que, amén de proyectarse sobre una experiencia jurídica europea, la Cátedra de la Universidad de La Habana fue una de las primeras de todo la región. En este sentido, todo esfuerzo en pos del rescate y la preservación de la tradición y la cultura jurídica del continente se hace hoy más que nunca indispensable.

\section{La Real y Pontificia Universidad de San Gerónimo de la Habana}

El 5 de enero de 1728 se fundaba oficialmente la Real y Pontificia Universidad de San Gerónimo de La Habana, primera universidad erigida en la isla de Cuba. Para ello, se necesitó de la Cédula Real dictada por Felipe V y de la Bula Papal emitida por Inocencio XIII, a la sazón soberano de España y sumo pontífice, respectivamente. En sus inicios, esta se mantuvo a cargo de la orden de los dominicos del convento de San Juan de Letrán. Contaba con una Facultad de Cánones y una de Leyes. En cuanto a este último aspecto debe advertirse que al margen de la administración clerical también proliferaron colegios particulares y de interés privado con real licencia especial para llevar a cabo la enseñanza 
jurídica. La creación de dichos centros obedecía al hecho de que la casa de altos estudios carecía de la infraestructura necesaria para acoger a todos aquellos que aspiraban a ingresar en sus aulas, más si consideramos que la carrera de leyes era precisamente una de las más codiciadas por la juventud criolla. Es así que José Gutiérrez de la Concha, quien fuera capitán general de la isla, dejó constancia de la existencia de dos colegios privados de La Habana y de Puerto Príncipe, que ofrecían cursos de derecho en aras de facilitar el acceso a tales estudios. Además de estos establecimientos existían cátedras de Jurisprudencia Civil y Canónica en los seminarios conciliares, tanto de la capital como de Santiago de Cuba. Estos últimos eran dependientes de la Universidad de La Habana, y sus cursos se incorporaban no con una periodicidad anual, sino que coincidían con los períodos de recepción de grados. ${ }^{1}$

Como afirma Elena Hernández Sandioca, la Real y Pontificia Universidad de San Gerónimo de La Habana, al igual que la mayoría de universidades peninsulares o americanas de la época, tenía entre sus misiones proveer a la Iglesia católica de clérigos curtidos en las ramas del saber ofrecidas en sus aulas. De esta forma, dichos egresados podían incorporarse a los diferentes cargos eclesiásticos y a otras funciones. ${ }^{2}$ El hecho de que la enseñanza universitaria se encontrara en manos de una orden religiosa implicaba, entre otras consecuencias, que estuviera permeada por las concepciones de la baja escolástica y por una enorme rigidez dogmática en cuanto a los conocimientos transmitidos y a los autores leídos. Esto, por supuesto, iba en detrimento de la calidad de la docencia, la cual daba la espalda al pensamiento racional y a los más novedosos avances en el campo científico.

Esta situación fue advertida incluso en el mismo seno del clero cubano. Durante los comienzos de la segunda mitad del siglo XVIII fray Juan Chacón, rector de la Universidad de La Habana, intentó sin éxito modernizar los planes de estudio, abogando por la inserción de las matemáticas y la física experimental. El prelado José Agustín Caballero, teólogo, filósofo y pionero de las doctrinas cartesianas en la isla, abogaba años después por una enseñanza libre que se hiciera eco "de la buena literatura y de los conocimientos esenciales de las ciencias y las artes” y que se colocara a la altura del estado en que por entonces se encontraba el saber humano. ${ }^{3}$ A ello hay que sumar la importante labor desempeñaría con posterioridad el obispo Juan José Días de Espada y

\footnotetext{
' ConCHA, José DE LA, Memorias sobre el estado político, gobierno y administración de la isla de Cuba, Madrid, José Trujillo, 1853, p. 58.

2 Hernández Sadolca, Elena, "La Universidad de La Habana, 1728-1898 (Implantación cultural, estatus científico y nacionalismo bajo el dominio español)", Historia de la educación: Revista universitaria, núm. 11, p. 77.

${ }^{3}$ Caballero, José Agustin, Obras, La Habana, Imagen Contemporánea, 1999, pp. 186-189.
} 
Fernández de Landa, entre cuyos logros figura el haberle dado un impulso inconmensurable al Real y Conciliar Colegio Seminario de San Carlos y San Ambrosio. Dicha institución, cuyas lecciones eran dictadas en castellano y no en latín, fue fundamental en la introducción y difusión del pensamiento ilustrado en Cuba y logró adquirir un gran renombre al punto de opacar a la Real y Pontificia Universidad de San Gerónimo de la Habana. ${ }^{4}$

Este nivel de atraso generalizado en el ámbito universitario repercutía directamente en la esfera de la jurisprudencia. En este sentido, durante los años iniciales de la Universidad de La Habana, la enseñanza del derecho estuvo signada por un predominio del derecho romano sobre el derecho patrio, que en este contexto que analizamos debe entenderse como el derecho español, dado el estatus colonial al que se veía constreñida Cuba por aquel entonces. El hecho de que la jurisprudencia romana copara los estudios jurídicos provocó una reacción por parte de algunos sectores del mundo intelectual. Una de las expresiones más trascendentes la sátira fue la que publicara en versos el profesor Prudencio Hechavarría y 0'Gavan. ${ }^{5}$

En ningún momento se pretendía restarle importancia al legado de los jurisconsultos de la Roma antigua, pero sí se trataba de hacer entender que el mismo no podía constituir por sí solo el epicentro del proceso forjador del jurista moderno. Era necesario por igual fomentar la impartición del derecho patrio, ya fuese el pasado o el actual, así como el discurrir entre los conocimientos históricos y filosóficos, en aras de una formación sólida con basamentos verdaderamente científicos. Las deficiencias de la enseñanza, existentes a causa de los factores mencionados, se dejaban ver sin tapujos en la práctica del ejercicio de la profesión. Tan evidentes eran las falencias que hacian semejante mella al foro, que en 1834, en la Aurora de Matanzas veía la luz un poema titulado "Rábula" donde se exponía el deterioro tanto moral como profesional de los abogados en el marco de sus faenas. ${ }^{6}$

Amén de estas cuestiones de índole esencialmente académicas, en la isla desde hace tiempo se venían gestando profundos cambios políticos, sociales y culturales con el impulso de una oligarquía criolla que cobraba cada vez más fuerza, devenida en lo que se conocería como sacarocracia. Esta poderosa clase social, imbuida por el pensamiento liberal y las doctrinas del librecambismo,

\footnotetext{
${ }^{4}$ Véase Rodriguez, José Ignacio, Vida de Don José de la Luz y Caballero, Nueva York, El Mundo Nuevo-La América Ilustrada, 1874, pp. 15-16.

${ }^{5}$ Hechavarria y O'Gavan, Prudencio, "Sátira contra la predilección del Derecho Romano en nuestras aulas y tribunales", Revista de la Facultad de Letras y Ciencias, vol. 29 [1919], pp. 257-277.

${ }^{6}$ Bachiller y Morales, Antonio, Apuntes para la historia de las letras y de la instrucción pública de la isla de Cuba, tomo 1, La Habana, P. Massana, 1859, pp. 185-186.
} 
esgrimía una concepción del progreso fuertemente vinculada con el conocimiento científico. De resultas, este grupo élite de mentalidad plantacionista potenciaría la idea de colocar el saber en función del desarrollo de las fuerzas y los medios de producción, en especial la producción azucarera, que había alcanzado cifras elevadísimas hasta convertirse en el principal producto exportable de la economía cubana. ${ }^{7}$

Uno de los más cultos e ilustres exponentes de este movimiento fue Francisco Arango y Parreño, quien en su Discurso sobre la Agricultura de la Habana y medios de fomentarla ${ }^{8}$ resumía los puntos cardinales del ideario defendido por la "sacarocracia” o "plantocracia." En 1825 había sido nombrado, a instancias del intendente de Hacienda Claudio Martínez de Pinillos, comisionado regio para la redacción de un Plan de Estudios para la isla de Cuba, en el cual asomaban algunos criterios reformadores que se encontraban en perfecta consonancia con los lineamientos a los cuales ya haciamos referencia. ${ }^{9}$

A las claras se podía constatar que los vientos de cambio soplaban y el proceso de modernización de la enseñanza universitaria, más tarde o más temprano, tendría que llegar bajo las premisas señaladas. No sólo apremiaba la necesidad de formar a los estudiantes sobre la base de los más adelantados conocimientos científicos de la época en aras de dejar atrás los rezagos de la escolástica, sino que la clase oligarca pujaba con insistencia en pos de sus intereses mercantiles. Es así como en 1842 en España se aprobó una reforma que se haría extensiva a Cuba e implicaría además la secularización de la universidad, que de Real y Pontificia ahora pasaba a llamarse Real y Literaria Universidad de La Habana. Con dicha reforma, la universidad quedó sujeta al control gubernamental.

Quedaba así implantada una modernización "centralizadora y burocratizante de la estructura educativa-superior" que se fundaba en los patrones napoleónicos de la reforma escolar. Esto implicaba una tendencia a la uniformidad y laicización de todos los ramos de la administración pública, condición que desde hacía tiempo ostentaba la educación en España gracias, en parte, a los reclamos de los sectores liberales. ${ }^{10}$ En lo concerniente al campo del derecho, la reforma de 1842 traería consigo importantes avances para la ciencia jurídica cubana y contribuiría a dejar sentados los cimientos de los estudios histórico-jurídicos.

\footnotetext{
7 Véase Moreno Fraginals, Manuel, Cuba/España. España/Cuba. Historia Común, Barcelona, Crítica, 1996, p. 150.

${ }^{8}$ Arango y Parreño, Francisco, "Discurso sobre la Agricultura de la Habana y medios de fomentarla", en Francisco Arango y Parreño, Obras, tomo 1, La Habana, Howson y Heines, 1888, pp. 53 y ss.

${ }^{9}$ Arango y Parreño, Francisco, "Plan de Estudios", Arango y Parreño, Francisco, Obras, t. II, La Habana, Imprenta, Encuadernación, Rayados y Efectos de Escritorio de Howson y Heines, 1889, pp. 547 y ss.

${ }^{10}$ Hernández Sadoica, Elena, "La Universidad de La Habana, 1728-1898 (Implantación cultural, estatus científico y nacionalismo bajo el dominio español)", Historia de la educación: Revista universitaria, núm. 11, p. 81.
} 


\section{Los inicios de los estudios histórico-jurídicos en Cuba}

Como ya se afırmaba en el acápite anterior, el año 1842 está signado como aquel que sirvió de umbral para el arribo de la modernidad a las aulas universitarias cubanas. Si bien no fue hasta unas décadas más tarde que se introdujo la historia del derecho como asignatura independiente, es a raíz de las reformas ilustradas de dicho año que se pueden determinar los orígenes de los estudios histórico-jurídicos en Cuba.

La reforma se hizo eco de muchos de los criterios que exigían por parte de los estudiantes de derecho la conjugación de las habilidades prácticas con la reflexión teórica, del mismo modo que se pretendía que los mismos fueran capaces de incursionar en otras ramas del saber que, sin importar que fueran afines o no a su área de conocimiento, les resultaran útiles a los efectos del ejercicio de su profesión. Es por ello que resultaba imprescindible para su formación de los alumnos se adentraran en los predios de disciplinas como la historia y la filosofía, por citar algunas. De esta manera, a la isla empezó a llegar la influencia de autores no sólo prevenientes de la península ibérica sino de otros países de Europa. Estos autores generalmente se leían bastante en España y, a través de la mediación metropolitana, alcanzaban determinada notoriedad en los círculos académicos de Cuba.

En lo que se refiere a los estudios histórico-jurídicos, una de las figuras más representativas de comienzos del siglo XIX fue Friedrich Carl von Savigny, fundador de la Escuela Histórica Alemana del Derecho y nombre clave en la configuración de la disciplina Historia del Derecho tal y como la conocemos hoy. Para Savigny, el derecho debía considerarse ante todo como un producto histórico que además constituía uno de los tantos elementos distintivos de los pueblos, como las tradiciones y el lenguaje. El derecho era por lo tanto un ente orgánico que residía en el espíritu del pueblo y que evolucionaba junto a este con independencia de la acción del legislador. ${ }^{11}$ De ahí que insistiera en la pertinencia de aproximarse a cualquier precepto o concepto jurídico siempre desde una perspectiva histórica, algo que establecería los presupuestos para la construcción de un derecho nacional que fuese propio, rico y eficaz, y que estuviese sustentado en una sólida formación científica. ${ }^{12}$

\footnotetext{
"SAvigny, Friedrich Carl von, De la vocación de nuestra época para la legislación y la ciencia del Derecho, Madrid, Universidad Carlos III de Madrid, 2015, pp. 20-21.

${ }^{12}$ Savigny, Friedrich Carl von, De la vocación de nuestra época para la legislación y la ciencia del Derecho, Madrid, Universidad Carlos III de Madrid, 2015, p. 81.
} 
Los postulados de la escuela histórica se fueron expandiendo considerablemente por todo el continente europeo, por lo que España, metrópoli de Cuba, obviamente no podía quedar al margen de este fenómeno. A partir de la reforma ilustrada de 1842, en virtud de la cual se refundía las Facultades de Leyes y Cánones en una sola Facultad de Jurisprudencia, se hizo claramente perceptible la tendencia de colocar a la historia en función de la dogmática jurídica, lo que constituía a una de las nociones centrales del programa de Savigny. Por tal motivo, las diferentes materias concebidas en el plan de enseñanza llevarían incorporado su respectivo componente histórico en clave de antecedentes, que luego viabilizarian la profundización de sus presupuestos teóricos y prácticos. Es así como se comenzaron a impartir asignaturas como Elementos e Historia del Derecho Romano, Elementos o Historia del Derecho Civil y Mercantil de España.

En este punto es preciso insertar a uno de los exponentes de la escuela histórica del derecho en Francia y un autor influyente tanto en España como Cuba. Nos referimos a Jean Luois Eugène Lerminier, quien se sintió desde muy joven identificado con el enfoque historicista de Savigny. Se doctoró en 1827 con una disertación sobre el tratado que había escrito este último sobre la posesión. ${ }^{13}$ Lerminier, en abierta oposición a la metodología de corte exegético que por entonces imperaba en Francia, sostiene una distinción entre derecho y legislación. Argumenta que el primero existe en la conciencia del hombre y en la vida de los pueblos, y que se manifiesta y desarrolla en la historia.

El derecho va a expresarse a través de una serie de símbolos e imágenes, entrelazado con la moral y la religión, y su exteriorización formal dependerá de muchos factores como el estado de desarrollo material y cultural de un pueblo, con la costumbre como fuente principal durante las edades más tempranas de la civilización. ${ }^{14}$ En consecuencia, la legislación, encarnada en los códigos modernos, venía a ser tan sólo una de las tantas formas de expresión del derecho, en este caso la correspondiente a la época en cuestión. Sin embargo, esta no podía verse de manera aislada respecto a todo el acervo, a los procesos y fenómenos que le habían precedido, sino que debía entenderse a modo de continuación y complemento de los mismos. ${ }^{15}$ Por estas razones, Lerminier aseguraba que el derecho debía estudiarse desde la perspectiva filosófica y desde la perspectiva histórica, pues sólo así, desde la aprehensión de estos dos elementos constitutivos sustanciales, se podría obtener un conocimiento cabal de su esencia. ${ }^{16}$

\footnotetext{
${ }^{13}$ Lerminier, Jean Luols Eugène, De Possessione Analytica Savignianeae Doctrinae Expositio, París, Guiraudet, 1827.

${ }^{14}$ LeRminIIER, Jean Luois Eugène, Introducción General a la Historia del Derecho, Barcelona, Librería de Don Antonio Sier, 1840, pp. 23-25.

${ }^{15}$ Lerminier, Jean Luols Eugène, De Possessione Analytica Savignianeae Doctrinae Expositio, Paris, Guiraudet, pp. 334-335.

${ }^{16}$ Lerminier, Jean Luois Eugène, De Possessione Analytica Savignianeae Doctrinae Expositio, Paris, Guiraudet, pp. 37-38.
} 
En mayo de 1842 la Introducción a la Historia del Derecho de Lerminier fue declarada en España como "obra útil para la enseñanza pública” por la Dirección General de Estudios, lo que significaba que esta debía ser tomada en cuenta a tales fines con preferencia sobre otras. Incluso en la Universidad de Salamanca dicha obra llegó a ser utilizada como libro de texto para la asignatura Prolegómenos del Derecho, explicada en aquella época por el profesor Juan Antonio Monleón. ${ }^{17}$ Como era de esperar, en Cuba el texto de Lerminier llegaría a tener una notable difusión de la cual daba fe José de la Luz y Caballero ${ }^{18}$ y la cual podremos constatar en los trabajos de algunos de los autores que serán abordados en el presente artículo.

Otra de las tendencias que fue acogida por los juristas cubanos decimonónicos fue el krausismo, el cual llegó a la isla a través de sus defensores en España. Uno de los autores en la isla que hizo más patente su filiación al pensamiento de Karl Christian Friedrich Krause fue Antonio Bachiller y Morales. Esto, además de ser asegurado por algunos de sus contemporáneos como José Manuel Mestre $^{19}$ y José Martí, ${ }^{20}$ se dejaba entrever en su Curso de Derecho Natural ${ }^{21}$ colmado de referencias a Heinrich Ahrens, quien fuera uno de los seguidores de Krause y quien logró transpolar muchas de las ideas filosóficas de este al área de la jurisprudencia. De hecho, a raíz de la reforma universitaria de 1863, el Curso de Derecho Natural de Ahrens ${ }^{22}$ se convertiría en la obra de referencia de la asignatura Filosofía del Derecho bajo la égida del catedrático José Manuel Mestre, quien había sido muy cercano a Bachiller y Morales y a otro de los reconocidos simpatizantes del krausismo, Nicolás Azcárate. ${ }^{23}$

En esta etapa que nos ocupa, en lo relativo a los estudios histórico-jurídicos sobresale el nombre de Antonio Prudencio López, catedrático de Historia y Elementos de Derecho Romano y que llegaría a ser nombrado decano de la Facultad de Derecho de la Universidad de La Habana. En el pensamiento de este profesor resulta visible el influjo de los postulados de Savigny y Lerminier pues, al igual que estos dos maestros europeos, confirma la idea de que el

\footnotetext{
${ }^{17}$ Véase Martinez Neira, Manuel y Mora Cañada, Adela, "La Historia del Derecho de Lerminier", Separata de Derecho, Historia y Universidades: Estudios dedicados a Mariano Peset, vol. 2, p. 151.

${ }^{18}$ Luz y Caballero, José de LA, "Cuarta réplica al Adicto sobre la cuestión de método", La polémica filosófica cubana. 1838-1839, Volumen I, La Habana, Imagen Contemporánea, 2000, pp. 297-299.

${ }^{19}$ Mestre, José Manuel, De la Filosofía en La Habana, La Habana, La Antilla, 1862, p. 76.

${ }^{20}$ Marti, José, "Antonio Bachiller y Morales", José Martí, Obras Completas, vol. 5, La Habana, Editorial de Ciencias Sociales, 1991, p. 147.

${ }^{21}$ Bachiller y Morales, Antonio, Elementos de la Filosofía del Derecho o Curso de Derecho Natural, La Habana, Imprenta del Tiempo, 1857.

${ }^{22}$ Ahrens, Heinkich, Curso de Derecho Natural o de Filosofía del Derecho, Formado con Arreglo al Estado de esta Ciencia en Alemania, Madrid, Boix, 1841.

${ }^{23}$ Véase SAPPEZ, DelPHInE, "El Krausismo en la Formación del Movimiento Reformista y Liberal en Cuba (siglo xix)", Revista de Indias (Madrid), Consejo Superior de Investigaciones Científicas, vol. 76, núm. 267, pp. 553.
} 
derecho positivo consta de dos elementos fundamentales: uno histórico y otro filosófico. Con base en la concatenación de estos debía ser visto en aras de su aprehensión total. ${ }^{24}$

Antonio Prudecio López no confunde al derecho con un producto artificial que encarna la obra consciente del legislador, más bien lo entiende como un fenómeno espontáneo inmanente a lo humano, a lo social. Lo ve como un ordenamiento regulador que emerge desde abajo, resultante de la interacción de los hombres y observado por estos en la dinámica de sus relaciones y de su vida. A tenor de estos criterios, el derecho está lejos de asociarse con los dictados de cualquier entidad de poder político. Por eso pondera a la costumbre como la manifestación jurídica suprema, siendo la ley solo una de sus vías de exteriorización, propia de una fase más avanzada dentro de su desarrollo histórico. ${ }^{25}$

En 1864, Antonio Prudencio López publicó su Reseña Histórica del Derecho de Ultramar bajo el presupuesto de que era la primera obra de este tipo que salía a la luz en Cuba. ${ }^{26}$ Dicho texto encerraba un trabajo de síntesis que se centraba en exponer de manera breve y sucinta los hitos elementales de la evolución histórica de la legislación ultramarina. Si bien se hizo especial énfasis en la Recopilación de Leyes de Indias, también se le dedicó un espacio a fuentes legales decimonónicas de España, como el Código de Comercio de 1829 y la Ley de Enjuiciamiento Mercantil de 1830. Este librito de apenas poco más de noventa cuartillas no solamente abarcaba las leyes de ultramar, sino que dirigía su atención igualmente hacia las instituciones políticas y administrativas del poder colonial, tomando en cuenta a las instituciones radicadas tanto en la metrópoli como en tierras americanas. Como era de esperar, se le reservaba un apartado a la organización político-administrativa en la isla de Cuba.

Hay algunos aspectos de índole más bien ideológica que a los ojos de hoy se le podría achacar a la obra de Antonio Prudencio López, como la falta de criticismo sobre determinadas normas o instituciones metropolitanas. En su trabajo se plantean algunos criterios bien bondadosos e incluso ingenuos respecto a temas como la regulación del estatus de los indios, particularmente en lo referente a las encomiendas. ${ }^{27}$ Pasa por alto las atrocidades y vejaciones por las que estos tuvieron que atravesar durante el proceso de conquista

\footnotetext{
${ }^{24}$ López, Antonio Prudencio, Oración Inaugural sobre el Derecho considerado bajos sus dos aspectos, filosófico e histórico, pronunciada en la apertura del año académico de 1865 a 1866 en la Real Universidad de La Habana, La Habana, Imprenta del Gobierno y Capitanía General, 1865, pp. 32-33.

${ }^{25}$ López, Antonio Prudencio, Oración Inaugural sobre el Derecho considerado bajos sus dos aspectos, filosófico e histórico, pronunciada en la apertura del año académico de 1865 a 1866 en la Real Universidad de La Habana, La Habana, Imprenta del Gobierno y Capitanía General, 1865, p. 6.

${ }^{26}$ López, Antonio Prudencio, Reseña Histórica del Derecho de Ultramar, La Habana, Imprenta "La Antilla", 1864, p. 5.

${ }^{27}$ Véase López, Antonio Prudencio, Reseña Histórica del Derecho de Ultramar..., p. 36.
} 
y colonización. Por lo demás, el texto en cuestión no carece de méritos y cumple con su finalidad: proveer a los estudiantes de una obra que complementara con noticias históricas del derecho de ultramar las lecciones de la Cátedra de Historia e Instituciones de Derecho Español. No pueden menos que aplaudirse los esfuerzos en aras de desarrollar un contenido hasta ese momento ausente de los estudios jurídicos en la Universidad de La Habana, cuya necesidad era de sobra reconocida.

Un aspecto que no podemos dejar de recalcar es que estamos posiblemente ante uno de los primeros manuales de historia del derecho de América Latina. Resulta interesante que el texto de Antonio Prudencio López apareciera más de una década antes que el Curso de Historia de Derecho Peruano de Román Alzamora, ${ }^{28}$ reputado como el primero en el continente y al que haremos referencia en el siguiente acápite. No es este el espacio para determinar si el de López fue el primer manual latinoamericano de historia del derecho; sostener tal afirmación requeriría entrar en detalles que nos apartarían del objeto de interés de este artículo. Pueden suscitarse como argumentos en contra que la obra de Alzamora se originó en el marco de una cátedra destinada exclusivamente al estudio de la historia del derecho, mientras que la de López servía de complemento a otra materia y no a una disciplina independiente. Igualmente se puede aducir que la obra de Alzamora se dedicaba al derecho histórico nacional peruano, mientras que López se enfocaba en un ordenamiento jurídico que si bien no era nacional, ni mucho menos latinoamericano, tampoco se puede entender como español en su sentido más estricto.

En fin, este tema podría ser objeto de un análisis mucho más profundo y podría generar un debate bien enriquecedor. Ahora bien, independientemente de ello, el texto de Antonio Prudencio López debe tomarse en cuenta a la hora de estudiar la historiografía jurídica de nuestra región.

\section{La Cátedra de Historia General del Derecho Español}

No fue hasta 1883 que en la Universidad de La Habana se creó la Cátedra de Historia General del Derecho Español a la luz del conocido Plan Gamazo, que había sido aprobado en España ese mismo año. Cabe recordar que, en el lapso comprendido entre la secularización de la enseñanza, en 1842, y el fin del dominio colonial español, en 1898, la suerte de la Universidad de La Habana estará estrechamente ligada a la universidad española. No sólo en la isla regirían

${ }^{28}$ Alzamora, Román, Curso de Historia del Derecho Peruano. Lecciones dadas en la Facultad de Derecho, Lima, Imprenta del Estado, 1876. 
básicamente los mismos planes de estudio vigentes en la metrópoli con puntuales modificaciones realizadas generalmente por razones de adaptabilidad, sino que la enseñanza del derecho se nutriría necesariamente de los textos y los autores provenientes de la península ibérica. Por esa razón, resulta imposible analizar el desarrollo de los estudios histórico-jurídicos en Cuba a lo largo del siglo XIX sin dirigir nuestra mirada hacia el Mediterráneo.

Manuel Martínez Neira indica que en España el interés por la historia del derecho vino dado justamente por el interés despertado hacia el derecho patrio, fenómeno que también se suscitó en Cuba. El estudio de este derecho, "también llamado real o nacional, no podía ser antes de la codificación sino histórico, pues significaba un enorme esfuerzo de búsqueda, ordenación y síntesis de una legislación milenaria, que se remontaba hasta el Liber". ${ }^{29} \mathrm{Si}$ bien antes del siglo XVIII las preocupaciones intelectuales de los jurisconsultos peninsulares se volcaban casi por completo hacia los textos clásicos romanos y canónicos, con posterioridad al momento apuntado comienzan a proliferar los estudios históricos sobre el derecho español, impulsados por el auge del movimiento de la Ilustración y recibiendo un apoyo institucional ostensible de manos de corporaciones científicas como la Real Academia de la Historia, la cual gozó de los auspicios de la monarquía. ${ }^{30}$

Finalmente, en 1883 mediante Real Decreto de 2 de septiembre se aprueba un nuevo programa de estudios promovido por el Ministro de Fomento Germán Gamazo, que insertaba algunas novedades como la creación de un curso preparatorio que cumplía con la función de depurar a aquellos alumnos que no lograran vencerlo y así evitar la saturación de las matrículas. Entre las seis asignaturas que conformaban dicho curso preliminar se encontraba Historia General del Derecho Español, la cual quedaba entonces configurada como una disciplina autónoma y de voluntaria asistencia. ${ }^{31}$ En palabras del connotado historiador Rafael Altamira y Crevea, esta historia del derecho se tenía como heredera directa de la historia del derecho civil que antes se impartía, y se centraba más en la historia externa que en la interna, y se enfocaba casi por completo en el estudio de las fuentes legales. ${ }^{32}$

El 16 de enero de 1884, los estudios de derecho eran nuevamente restructurados mediante otro Real Decreto. Su artífice esta vez fue el nuevo ministro

\footnotetext{
${ }^{29}$ Martinez Neira, Manuel, Los origenes de la Historia del Derecho en la universidad española, Madrid, Universidad Carlos III de Madrid - Dykinson, 2000, p. 74.

${ }^{30}$ Véase Escudero, José Antonio, Curso de Historia del Derecho Español. Fuentes e instituciones político-administrativas, Madrid, Solana e Hijos, 1995, pp. 47-48.

${ }^{31}$ Martinez NelRa, Manuel, Los orígenes de la Historia del Derecho en la universidad española, Madrid, Universidad Carlos III de Madrid - Editorial Dykinson, 2000, pp. 96-97.

${ }^{32}$ Altamira, Rafael, La Enseñanza de la Historia, Madrid, Libreria de Victoriano Suárez, 1895, p. 454.
} 
de Fomento, Ángel Carvajal y Fernández de Córdoba, marqués de Sardoal. En relación con la historia general del derecho, el cambio más significativo es que acorde con este nuevo plan pasa de ser una asignatura preparatoria a una de estudio último, que no podía ser examinada sin antes haber concluido todas las materias de la licenciatura. Otro dato interesante es que para obtener el doctorado se exigía cursar un grupo de disciplinas de corte histórico, entre las cuales se encontraban Instituciones Civiles y Penales de los Pueblos Antiguos y Modernos e Instituciones Políticas de los Pueblos Antiguos y Modernos. ${ }^{33}$

El Plan de Sardoal también pecó de efímero y fue sustituido por un nuevo programa mediante Real Decreto de 14 de agosto de 1884 que en realidad no implicó grandes alteraciones para la historia general del derecho, salvo que, en virtud de la libertad de matriculación regulada, podía ser cursada en cualquier momento de la carrera, aunque se recomendaba hacerlo durante en el tercer año. Este nuevo plan también acogía una buena cantidad de asignaturas históricas, entre las cuales destacaban Instituciones de Derecho Público de los Pueblos Antiguos y Modernos e Instituciones de Derecho Privado de los Pueblos Antiguos y Modernos. ${ }^{34}$

Es así como, al amparo de la legislación española, se instaura en Cuba la Cátedra de Historia del Derecho que vino a ser una de las primeras de América Latina en su tipo, posiblemente la segunda. La primera Universidad del continente latinoamericano en abrir una Cátedra de Historia del Derecho fue la de San Marcos, en Perú, habilitada en 1875 y con el profesor Román Alzamora a la cabeza. ${ }^{35}$ De la pluma de este docente salió el manual al que hicimos referencia, que si bien destinaba la mayor parte de sus páginas a la evolución histórica de las instituciones y las reglas jurídicas del Perú, tenía a bien dedicarle unos cuantos capítulos al derecho español y a la organización político-jurídica de los Incas. Pero lo cierto es que Cuba contó con la Cátedra de Historia General del Derecho incluso mucho antes que algunos países del continente como Argentina, Chile y México, donde dichas cátedras vinieron a florecer a principios del siglo xx.

Nos encontramos en una época donde el positivismo se halla en pleno estado de efervescencia, y su metodología, propia de las ciencias naturales, alcanza a permear lo que hoy conocemos por ciencias sociales. De ahí que el análisis positivo de los fenómenos sociales, incluyendo los de naturaleza jurídica, exigía

\footnotetext{
${ }^{33}$ Martinez Neira, Manuel, Los origenes de la Historia del Derecho en la universidad española, Madrid, Universidad Carlos III de Madrid - Editorial Dykinson, 2000, p. 98.

${ }^{34}$ Martinez Nelra, Manuel, Los orígenes de la Historia del Derecho en la universidad española, Madrid, Universidad Carlos III de Madrid - Editorial Dykinson, 2000, pp. 99-100.

${ }^{35}$ Véase Ramos Núñez, Carlos, La ley, la palabra y la vida, Perú, Legisprudencia, 2014, p. 20.
} 
una mirada a través del prisma de la historia. Esta última se consideraba como el laboratorio en el cual dichos fenómenos podían observarse en su constante dinámica de transformación y restructuración.

Es por eso que en la Universidad de La Habana de finales del siglo XIx la tendencia de concebir a la historia como la base de todo examen científico de las instituciones jurídicas del presente fue asimilada no solo por la Cátedra de Historia General del Derecho Español, sino también por el marco de otras materias. En este sentido, resaltan los casos de profesores como el penalista José Antonio González Lanuza y el procesalista Ricardo Dolz y Arango, quienes en sus programas daban cabida a la explicación histórica como antesala de los presupuestos teóricos y doctrinales de sus respectivas materias. ${ }^{36}$

Asimismo, Antonio Sánchez de Bustamante y Sirvén, quizás el jurista cubano de mayor celebridad mundial, en el primer tomo de su Tratado de Derecho Internacional Privado, ponderaba el método histórico, más que para desenterrar "curiosidades científicas" para poder "construir teóricamente organismos que alcancen la mayor perfección posible." ${ }^{37}$

Adentrándonos ya de lleno en la Cátedra cubana de Historia General del Derecho Español, durante el período comprendido entre su apertura, en 1883, y el cese del dominio colonial, en 1898, serían dos profesores los encargados de estar sucesivamente al frente de la misma. Hablamos de José María Céspedes y Orellano y Juan Francisco 0'Farril y Chappotín. Aparentemente, ninguno de estos docentes dejó escrito algún manual u obra general destinada a la impartición de la asignatura. Por fortuna, sí contamos con varios trabajos de su autoría que nos permiten inferir algunas de sus líneas metodológicas, así como algunos criterios en relación con el alcance y la finalidad que le otorgaban a la disciplina, los cuales serán abordados de inmediato.

Empezamos con José María Céspedes y Orellano, quien nació en Bayamo el 10 de abril de 1829. Graduado de Licenciado en Jurisprudencia por la Universidad de La Habana, en 1852 y con el título de Doctor, en 1856, ocuparía años más tarde la Cátedra de Derecho Penal y Procedimientos Civiles y Criminales, sustituyendo a Antonio Zambrana. ${ }^{38}$ A razón de ello, escribió una manual

\footnotetext{
${ }^{36}$ Véase González Lanuza, José Antonio, Programa de Derecho Penal. Curso 1893-1894, La Habana, La Moderna, 1893, pp. 9 y ss.; Dolz y ARANGo, RicARDo, "Ventajas del plan y del método de enseñanza desarrollados en el programa de Derecho Procesal Civil, Penal, Canónico y Administrativo, y Teoría y Práctica de redacción de instrumentos públicos", Revista del Foro, tomo 3, p. 3.

${ }^{37}$ Sánchez de Bustamante y Sirvén, José Antonio, Tratado de Derecho Internacional Privado, tomo 1, La Habana, La Universal, 1896, pp. 173-174.

${ }^{38}$ Véase Calcagno, Francisco, Diccionario bibliográfico cubano, New York, N. Ponce de León, 1878, pp. 190-191.
} 
sobre materia procesal. ${ }^{39}$ A raíz del estallido de la guerra de independencia, se estableció durante unos años en Costa Rica, país que recibiría a un número elevado de familias cubanas que huían de la beligerancia y donde desarrolló una importante actividad académica.

Céspedes y Orellano tuvo la oportunidad de incorporarse a la Universidad de Santo Tomás, donde ejerció las cátedras de Derecho Internacional, Derecho Público, Derecho Romano y Filosofía Racional. Tan grande fue la labor Céspedes en Costa Rica, y tan alto fue su impacto, que es reconocido como el introductor de la filosofía positivista en dicho país. ${ }^{40}$ En efecto, este siempre mostró una gran admiración hacia la figura de Auguste Comte y el sistema filosófico que creó, el cual consideraba superior al resto de las corrientes existentes por estar basado en hechos reales y comprobados, no en hipótesis de carácter metafísico. ${ }^{41}$

Finalizada la guerra regresó a Cuba y pudo reincorporarse a la Universidad de La Habana, donde poco antes de convertirse en el catedrático de Historia General del Derecho Español ocupó la Cátedra de Legislación Comparada. Para el cumplimiento de esta tarea proponía expandir los límites de esta materia hacia los confines de la historia crítica del estado social y de las leyes que habían regido los pueblos antiguos del Oriente, de Grecia y Roma; todo eso para después redirigirse al estudio de la historia crítica del estado social y de las leyes que regían las sociedades modernas. Un punto que no dejaba de recalcar era que para cumplir satisfactoriamente el itinerario trazado se hacía necesario recurrir a la filosofía del derecho, puesto que todo ese caudal de conocimientos debía sustentarse en principios sólidos y certeros. ${ }^{42}$

$\mathrm{Al}$ examinar el alcance que pretendía darle Céspedes a la Cátedra de Legislación Comparada, podemos vislumbrar el papel que le otorga al análisis histórico. Una cuestión fundamental en su pensamiento es que para este toda mirada al pasado jurídico debía estar justificada y no podía obedecer a fines banales e infructuosos. La historia no podía salir a relucir por mero alarde de erudición. No era factible abusar de ella con el simple afán de rellenar cuartillas, pues su uso indiscriminado no hacía más que denotar incapacidad

\footnotetext{
${ }^{39}$ Céspedes y Orellano, José Maria, Elementos teórico-prácticos de procedimientos civiles con aplicación a la isla de Cuba, La Habana, La Antilla, 1862.

${ }^{40}$ Véase Vargas Araya, Armando, El Doctor Zambrana, San José, Costa Rica, Universidad Estatal a Distancia, 2006, pp. 37-38.

${ }^{41}$ Véase Céspedes y Orellano, José Maria, "El Comtismo", José María Céspedes y Orellano, Discursos, escritos y artículos, La Habana, Teniente Rey 23, 1895, p. 282.

${ }^{42}$ Véase Céspedes y Orellano, José MariA, "Discurso de Apertura de la Cátedra de Legislación Comparada en la Universidad de La Habana en el Año Académico de 1880 a 1881", en José María Céspedes y Orellano, Discursos, escritos y artículos, La Habana, Teniente Rey 23, 1895, p. 2.
} 
de generar ideas propias y generales. ${ }^{43}$ Céspedes entendía que todos los conocimientos resultaban provechosos, pero ante la imposibilidad de abarcarlos en su totalidad, veía prudente concentrarse en aquellos que con independencia de su naturaleza u objeto fueran los de mayor utilidad y los imprescindibles para el óptimo desempeño de la profesión jurídica. ${ }^{44}$

Ahora bien, estas opiniones no implicaban para nada el rechazo a la perspectiva histórico-jurídica, ya que no tuvo miramientos en recalcar que el derecho tenía que ser estudiado en la historia, "subiendo hasta sus orígenes concretos y descendiendo a sus infinitas evoluciones étnicas y relativas siempre”. ${ }^{45}$

José María Céspedes y Orellano estaba consciente del carácter de la historicidad como un rasgo consustancial al fenómeno jurídico. El derecho no puede entenderse aislado de la sociedad que le da vida, ya que de las modulaciones de ésta depende su desenvolvimiento y evolución.

El Derecho, como todo lo que se refiere al hombre, está sujeto a evoluciones y transformaciones sucesivas y constantes. De otro modo no se comprendería el perfeccionamiento, ni el progreso se convertiría en una ley de la humanidad [...] El Derecho se ha formado como las lenguas, lentamente y por virtud de las necesidades crecientes y distintas en cada agrupación. Y si debe tenerse en cuenta la naturaleza humana para estudiar y comprender el móvil de las determinaciones y de los actos individuales y sociales, no debe ni puede olvidarse la inconstancia y relatividad que envuelve en sí misma. ${ }^{46}$

El derecho, la manera en que se exprese, se entienda y se realice, dependerá además de una serie de condiciones relativas no sólo a cada momento histórico, sino a factores circunstanciales referentes al ámbito espacial en el que este se desarrolle. De ahí que el docente declarara:

Las leyes que para su gobierno formularon las distintas sociedades humanas, en el tiempo y en el espacio, han tenido que responder al estado progresivo de la comunidad y al desenvolvimiento particular de

\footnotetext{
${ }^{43}$ Véase Céspedes y Orellano, José María, "Abuso de la Historia", en José María Céspedes y Orellano, Discursos, escritos y artículos, La Habana, Teniente Rey 23, 1895, pp. 435-436.

${ }^{44}$ Céspedes y Orellano, José Maria, El Derecho, su clasificación y sus relaciones con las otras ciencias, La Habana, Imprenta del Gobierno y Capitanía General, 1886, p. 4.

${ }^{45}$ CÉspedes y Orellano, José MariA, El Derecho, su clasificación y sus relaciones con las otras ciencias, La Habana, Imprenta del Gobierno y Capitanía General, 1886, p. 5.

${ }^{46}$ Céspedes y Orellano, José Maria, El Derecho, su clasificación y sus relaciones con las otras ciencias, La Habana, Imprenta del Gobierno y Capitania General, 1886, pp. 11-12.
} 
las aptitudes individuales. La justicia civil y la justicia criminal, indispensables para mantener el lazo de unión y para apretarle, no pudieron ser iguales en todas las épocas ni en todos los grupos. Las leyes han sufrido las transformaciones necesarias y consiguientes a las evoluciones periódicas y constantes del ser a que se aplican. Esas reglas de la vida común son el producto natural de las condiciones internas y externas de los asociados. ${ }^{47}$

Hasta aquí ha sido posible identificar algunas de las directrices principales del pensamiento de José María Céspedes y Orellano y de su visión historicista del fenómeno jurídico. Los criterios que hemos expuesto nos permiten aseverar que su concepción de la historia del derecho se sitúa muy próxima a disquisiciones de naturaleza sociológica. Al percibir al derecho como ordenamiento que no era sino resultado natural de las relaciones sociales de convivencia (cuyas manifestaciones variaban según las diferentes fases del desarrollo histórico), no temía afirmar la existencia de un régimen jurídico incluso en el seno de las sociedades más primitivas, en las cuales podía vislumbrar relaciones tanto de derecho público como de derecho privado, aunque fuese en estado rudimentario. De hecho, en ese tipo de relaciones, Céspedes encontraba las expresiones germinales de las dinámicas iusprivatistas y iuspublicistas de la era moderna. ${ }^{48}$ Otro aspecto que se debe tomar en cuenta en este sentido es que, a la hora de definir el derecho público y el derecho privado de los pueblos antiguos y modernos, Céspedes los consideraba, respectivamente, como una historia general de sus sistemas de gobiernos, de sus constituciones y de sus códigos, para el caso del primero; mientras que el segundo lo entendía como la historia de sus instituciones civiles. ${ }^{49}$

El profesor que sustituyó a Céspedes en la Cátedra de Historia General del Derecho Español desde 1891 fue, como ya mencionábamos, Juan Francisco 0’Farril y Chappotín. Además de profesor universitario, se desempeñó en la política; llegó a integrar el gabinete del presidente Tomás Estrada Palma durante los primeros años de la República, una vez alcanzada la independencia. En la obra de 0'Farrill se evidencia una inclinación hacia la historia de la legislación y las instituciones, como consta en su conferencia sobre la España romana. En

\footnotetext{
${ }^{47}$ Céspedes y Orellano, José Maria, "Antropología y Derecho Penal", Revista Cubana. Periódico Mensual de Ciencias, Filosofía, Literatura y Bellas Artes, tomo 1, La Habana, Soler, Álvarez y Comp., 1885, p. 13.

${ }^{48}$ Céspedes y Orellano, José MaRia, El Derecho, su clasificación y sus relaciones con las otras ciencias, La Habana, Imprenta del Gobierno y Capitanía General, 1886, pp. 14-15.

${ }^{49}$ Céspedes y Orellano, José Maria, El Derecho, su clasificación y sus relaciones con las otras ciencias, La Habana, Imprenta del Gobierno y Capitania General, 1886, pp. 17-18.
} 
esta última, además, reivindica la importancia del derecho público romano como portador de principios informadores de la ciencia política moderna. ${ }^{50}$

Otra de sus obras fundamentales quedó contenida en su discurso para la obtención del grado de doctor en derecho, el cual versaba sobre los fundamentos teóricos e históricos de la legítima. Particularmente en este discurso defiende el enfoque filosófico, pero sobre todo el histórico, a la hora de encarar el estudio del derecho.

Atender en el estudio del Derecho al elemento histórico prescindiendo del filosófico, es desconocer la importancia extraordinaria de este; y por el contrario desatender las enseñanzas siempre respetables de la Historia, es olvidar que el destino de la humanidad se realiza en el tiempo y que los acontecimientos tienen influencia directa en la constitución de aquella, sus aspiraciones y tendencias. La Filosofía tiene la teoría del Derecho, la Historia su práctica, ambas deben ser consideradas como indispensables para el progreso de la ciencia. ${ }^{51}$

Para Juan Francisco 0'Farrill era justamente en la historia donde había que ir a buscar el fundamento de toda institución. No era sino hurgando en los confines temporales más remotos como se vislumbrarian las causas que habían propiciado el origen de las mismas y condicionado su evolución posterior. Hasta las disposiciones del derecho positivo, incluso "cuando en muchos casos no tengan un origen más elevado que la ley formada por los hombres, encuentran, sin embargo, su existencia justificada por las necesidades sociales que vienen a satisfacer". ${ }^{52}$ Sin embargo, este ejercicio retrospectivo que proponía 0'Farrill no podía limitarse simplemente al establecimiento de causalidades. Tenía que ir más allá y en consecuencia debía propiciar el examen minucioso de las características de la institución, debía coadyuvar a sopesar los resultados y consecuencias que históricamente habían traído consigo su aplicación práctica.

\footnotetext{
${ }^{50}$ O'Farrill, Juan Francisco, La España romana. Discurso leído en la Apertura del $10^{\circ}$ curso de la Academia de Derecho, La Habana, La Universal, 1895, pp. 10-11.

${ }^{51}$ O'Farril y Chappotin, Juan Francisco, Discurso para el doctorado en Derecho, sección del Civil y el Canónico, leído y sostenido el 18 de junio de 1884 por el Ldo. Juan Francisco O'Farril y Chappotín, La Habana, Soler, Álvarez y Compañía, 1884, p. 6.

${ }^{52}$ O'Farril y Chappotin, Juan Francisco, Discurso para el doctorado en Derecho, sección del Civil y el Canónico, leído y sostenido el 18 de junio de 1884 por el Ldo. Juan Francisco O'Farril y Chappotín, La Habana, Soler, Álvarez y Compañia, 1884, p. 7.
} 
Todo esto llevaría necesariamente a la formación de un juicio crítico sobre la institución objeto del análisis. ${ }^{53}$

Anteriormente, lamentábamos el hecho de que ni Céspedes ni 0’Farrill, al parecer, habian redactado manual u obra general alguna dirigida a la impartición de la asignatura Historia General del Derecho Español. Sin embargo, el segundo sí tuvo a bien publicar el programa por él seguido a tales efectos, lo cual nos brinda al menos los temarios y la estructura del curso. ${ }^{54}$ De acuerdo con lo consignado en dicho programa, la materia constaba de 102 lecciones. Las primeras de estas seis lecciones estaban destinadas a cuestiones conceptuales y metodológicas, donde se abordaban las teorías de autores como Savigny y Giambattista Vico. Las siguientes lecciones se dedicaban a la evolución histórica de la legislación y las instituciones españolas desde la antigüedad hasta la época moderna. Un punto que debemos destacar es que las últimas lecciones se centraban en la legislación ultramarina desde los inicios del proceso de colonización hasta el siglo xIx. En estos últimos apartados se hacía referencia particular Cuba, haciendo hincapié sobre todo en la vigencia que tuvieron en su territorio algunos de los códigos españoles.

En 1898 cesaría el dominio colonial español en la isla y, después de un breve lapso de intervención militar norteamericana, nacería en 1902 la República de Cuba. La consecución de la independencia y la instauración del nuevo orden republicano trajeron consecuencias no sólo en el ámbito político sino en la esfera cultural e intelectual. La universidad de La Habana sufriría profundas transformaciones que empezaron con la sustitución de los planes de estudio vigentes durante la última etapa del régimen colonial. Aunque esto no significó la supresión de los estudios histórico-jurídicos, sí implicó la desaparición de la asignatura Historia General del Derecho Español. Las disciplinas de corte iushistórico proliferarían a lo largo de la primera mitad del siglo xx, pero habría que esperar décadas para que en las aulas universitarias del país asomara una historia general del derecho cubano.

\section{Conclusiones}

Como ya se aseguraba desde la introducción del presente artículo, el origen y desarrollo de la historia del derecho en Cuba como disciplina científica fue una

\footnotetext{
${ }^{53}$ O'FarRil y Chappotin, Juan Francisco, Discurso para el doctorado en Derecho, sección del Civil y el Canónico, leido y sostenido el 18 de junio de 1884 por el Ldo. Juan Francisco O'Farril y Chappotín, La Habana, Soler, Álvarez y Compañia, 1884, p. 32.

${ }^{54}$ O'FarRiLl, Juan Francisco, Programa de Historia General del Derecho Español, La Habana, Imprenta y Papelería "La Universal" de Ruiz y Hermano, 1892.
} 
temática ignorada por los estudiosos del derecho del país a lo largo de todo el siglo xx. En las décadas más recientes, dicho fenómeno podría justificarse, entre otras razones, por la falta de interés que suscitan en nuestros tiempos los estudios histórico-jurídicos, algo que no es exclusivo del contexto cubano, ni siquiera del latinoamericano. En cuanto a los albores del siglo xx, una posible explicación podría ser el nuevo escenario republicano en el que se trata de sedimentar una cultura nacional, dentro de lo cual se engloba la construcción de una ciencia jurídica propia, y por ende se evita en muchos sentidos retrotraerse al pasado colonial inmediato y se generan ciertas actitudes esquivas a lo español, no tanto a modo de rechazo como en interés de superar la experiencia pretérita y mirar hacia el futuro. El caso es que la historiografía jurídica, así como la ciencia del derecho durante la etapa decimonónica, sigue siendo hasta el día de hoy un territorio poco explorado.

Cierto es que la historiografía jurídica cubana del siglo XIX, en especial la desarrollada en el marco de la Cátedra de Historia General del Derecho Español por parte de sus titulares, se proyectaba sobre una realidad jurídica muy distinta a la de la isla. Sus mismas pretensiones academicistas y su sometimiento al control centralizado de la estructura institucional educativa de la metrópoli la mantuvieron por demás al margen de una serie de acontecimientos que deberían en principio haber sido objeto de su interés. Hablamos, por ejemplo, de la historiografía producida por la oligarquía criolla desde el siglo precedente con un marcado carácter de reivindicación ideológica e identitaria, o el intenso debate historiográfico suscitado en la segunda mitad del siglo XIX.

A pesar de las cuestiones recién planteadas, no se le debe restar relevancia alguna a la historiografía jurídica del siglo XIX, pues esta hizo gala de un considerable nivel científico apegado a las corrientes doctrinales más trascendentes de su época. Aportó un panorama de la mentalidad y filiación de nuestros cultores de la ciencia del derecho por aquel entonces. Asimismo, se ha podido constatar que, amén de la directa e inevitable influencia procedente de España, el origen y posterior desarrollo de las disciplinas histórico-jurídicas estuvieron condicionados en muchos aspectos a circunstancias acaecidas en la isla, dígase un efervescente clima intelectual y un crecimiento económico que pujaba por nuevos esquemas. En especial esta etapa correspondiente a la apertura de la Cátedra de Historia General del Derecho Español fue medular en la forja de una nueva generación de juristas que durante la primera mitad del siglo xx estarían a la vanguardia de la ciencia jurídica latinoamericana. Sobradas son las razones para no desterrar el tema que nos ha ocupado de nuestra área de interés, y no sólo eso, sino que aún quedan muchas aristas esperando a ser desentrañadas. 


\section{Bibliografía}

Altamira, Rafaet, La Enseñanza de la Historia, Madrid, Librería de Victoriano Suárez, 1895. Alzamora, Román, Curso de Historia del Derecho Peruano. Lecciones dadas en la Facultad de Derecho, Lima, Imprenta del Estado, 1876.

Arango y Parreño, Francisco, "Discurso sobre la Agricultura de la Habana y medios de fomentarla”, en Francisco Arango y Parreño, Obras, tomo 1, La Habana, Howson y Heines, 1888.

Arango y Parreño, Francisco, "Plan de Estudios", en Francisco Arango y Parreño,

Obras, tomo 2, La Habana, Howson y Heines, 1889.

Ahrens, Heinrich, Curso de Derecho Natural o de Filosofía del Derecho, Formado con

Arreglo al Estado de esta Ciencia en Alemania, Madrid, Boix, 1841.

Bachiller y Morales, Antonio, Apuntes para la historia de las letras y de la instrucción

pública de la isla de Cuba, tomo 1, La Habana, P. Massana, 1859.

Bachiller y Morales, Antonio, Elementos de la Filosofía del Derecho o Curso de Derecho

Natural, La Habana, Imprenta del Tiempo, 1857.

Caballero, José Agustín, Obras, La Habana, Imagen Contemporánea, 1999.

Calcagno, Francisco, Diccionario bibliográfico cubano, New York, N. Ponce de León, 1878.

CÉSPEDES y ORellano, José María, “Abuso de la Historia”, José María Céspedes y Orellano, Discursos, escritos y artículos, La Habana, Establecimiento Tipográfico, Teniente Rey 23, 1895.

Céspedes y Orellano, José María, “Antropología y Derecho Penal”, Revista Cubana. Periódico Mensual de Ciencias, Filosofía, Literatura y Bellas Artes, tomo 1, La Habana, Soler, Álvarez y Comp., 1885.

Céspedes y Orellano, José María, "El Comtismo", José María Céspedes y Orellano, Discursos, escritos y artículos, La Habana, Teniente Rey 23, 1895.

CÉSPEDES y ORELlano, José MaRÍA, Elementos teórico-prácticos de procedimientos civiles con aplicación a la isla de Cuba, La Habana, La Antilla, 1862.

Céspedes y Orellano, José María, "Discurso de Apertura de la Cátedra de Legislación Comparada en la Universidad de La Habana en el Año Académico de 1880 a 1881”, en José María Céspedes y Orellano, Discursos, escritos y artículos, La Habana, Teniente Rey 23, 1895.

Concha, José DE LA, Memorias sobre el estado político, gobierno y administración de la isla de Cuba, Madrid, José Trujillo, 1853.

CésPedes y ORellano, José María, El Derecho, su clasificación y sus relaciones con las otras ciencias, La Habana, Imprenta del gobierno y Capitanía General, 1886.

Dolz y ARANGo, Ricardo, "Ventajas del plan y del método de enseñanza desarrollados en el programa de Derecho Procesal Civil, Penal, Canónico y Administrativo, y Teoría y Práctica de redacción de instrumentos públicos", Revista del Foro, tomo 3, segunda época, 1895. 
Escudero, José Antonio, Curso de Historia del Derecho Español. Fuentes e instituciones político-administrativas, Madrid, Solana e Hijos, 1995.

González Lanuza, José Antonio, Programa de Derecho Penal. Curso 1893-1894, La Habana, La Moderna, 1893.

Hechavarría y O’Gavan, Prudencio, “Sátira contra la predilección del Derecho Romano en nuestras aulas y tribunales”, Revista de la Facultad de Letras y Ciencias, vol. 29 [1919].

Hernández SAdoica, Elena, "La Universidad de La Habana, 1728-1898 (Implantación cultural, estatus científico y nacionalismo bajo el dominio español)”, Historia de la educación: Revista universitaria, núm. 11.

Lerminier, Jean Luois Eugène, De Possessione Analytica Savignianeae Doctrinae Expositio, París, Guiraudet, 1827.

LERMInIER, JeAn LuOIS EugĖne, Introducción General a la Historia del Derecho, Barcelona, Librería de Don Antonio Sier, 1840.

López, Antonio Prudencio, Oración Inaugural sobre el Derecho considerado bajos sus dos aspectos, filosófico e histórico, pronunciada en la apertura del año académico de 1865 a 1866 en la Real Universidad de La Habana, La Habana, Imprenta del Gobierno y Capitanía General, 1865.

Imprenta "La Antilla”, 1864. Reseña Histórica del Derecho de Ultramar, La Habana,

LuZ y CABAlLero, JosÉ DE LA, “Cuarta réplica al Adicto sobre la cuestión de método”, La polémica filosófica cubana. 1838-1839, Volumen I, La Habana, Imagen Contemporánea, 2000.

Martí, José, “Antonio Bachiller y Morales”, José Martí, Obras Completas, vol. 5, La Habana, Editorial de Ciencias Sociales, 1991.

Martínez Neira, Manuel, Los orígenes de la Historia del Derecho en la universidad española, Madrid, Universidad Carlos III de Madrid - Editorial Dykinson, 2000. Martínez Neira, Manuel y Mora Cañada, Adela, "La Historia del Derecho de Lerminier”, Separata de Derecho, Historia y Universidades: Estudios dedicados a Mariano Peset, vol. 2.

Mestre, José Manuel, De la Filosofía en La Habana, La Habana, La Antilla, 1862.

Moreno Fraginals, Manuel, Cuba/España. España/Cuba. Historia Común, Barcelona,

Crítica, 1996.

O’Farril, JuAn Francisco, La España romana. Discurso leido en la Apertura del $10^{\circ}$ curso de la Academia de Derecho, La Habana, La Universal, 1895.

O’FARril y ChapotTín, JuAn Francisco, Discurso para el doctorado en Derecho, sección del Civil y el Canónico, leído y sostenido el 18 de junio de 1884 por el Ldo. Juan Francisco O’Farril y Chappotín, La Habana, Soler, Álvarez y Compañía, 1884.

Ramos Núñez, Carlos, La ley, la palabra y la vida, Perú, Legisprudencia, 2014. Rodríguez, José Ignacio, Vida de Don José de la Luz y Caballero, Nueva York, El Mundo Nuevo-La América Ilustrada, 1874. 
SÁnchez de Bustamante y Sirvén, José Antonio, Tratado de Derecho Internacional Privado, tomo I, La Habana, La Universal, 1896.

SAPPEZ, Delphine, "El Krausismo en la Formación del Movimiento Reformista y Liberal en Cuba (siglo xIX)”, Revista de Indias (Madrid), Consejo Superior de Investigaciones Científicas, vol. 76, núm. 267.

SAVIgny, Friedrich CARl von, De la vocación de nuestra época para la legislación y la ciencia del Derecho, Madrid, Universidad Carlos III, 2015.

Vargas Araya, Armando, El Doctor Zambrana, San José, Costa Rica, Universidad Estatal a Distancia, 2006. 